\title{
TRICHOSTATIN A, A POTENTIAL DRUG FOR TREATMENT OF ANIMAL BABESIA INFECTIONS
}

\author{
T. Nyamjargal' ${ }^{1}$ N. Oshima ${ }^{1}$, X.Xuan'1, I. Igarashi ${ }^{1}$, T. Munkhjargal ${ }^{2}$, H. Suzuki ${ }^{1}$ \\ 1-National Research Center for Protozoan Diseases, \\ Obihiro University of Agriculture and Veterinary Medicine, Japan \\ 2-Institute of Veterinary Medicine, Mongolia \\ nyama18@yahoo.com
}

\begin{abstract}
In the present study, we evaluated the inhibitory effect of trichostatin A on the asexual growth of bovine, equine, and canine Babesia parasites in vitro as well as on the in vivo growth of Babesia microti (B.microti) in mice. The growth of Babesia bovis (B.bovis), Babesia bigemina (B.bigemina), Babesia caballi (B.caballi), Theileria equi (T.equi), and Babesia gibsoni (B.gibsoni) species was significantly inhibited $(P<0.05)$ by very low concentrations of trichostatin $A\left(I C_{50}\right.$ values $=2.6,2.4,2.3,2.4$, and $2.3 \mathrm{nM}$, respectively). Furthermore, in B.microti-infected mice, trichostatin A caused significant higher $(P<0.05)$ inhibition of the growth of B.microti at the dose of $2 \mathrm{mg} / \mathrm{kg}$ body weight than that in the control group. These results indicated the trichostatin A might be a chemotherapeutic agent for treatment of babesiosis.
\end{abstract}

KEY WORDS: Chemotherapy; in vitro; in vivo; parasites.

\section{INTRODUCTION}

Babesia is an intraerythrocytic protozoan parasite that is transmitted to animals by ticks and babesiosis is also important with regard to zoonotic diseases. Recent our studies have shown that the use of histone deacetylase inhibitor, apicidin, can inhibit enzyme activity of recombinant B.bovis histone deacetylase protein (1) and the growth-inhibitory effect on Babesia

\section{MATERIALS AND METHODS}

Inhibitory effects of Trichostatin A upon the B.bovis, B.bigemina, B.gibsoni, B.caballi and T.equi growth were examined as previously described (2 and 3). The in vivo growth inhibition assay for parasites both in vitro and in vivo. (2). Trichostatin $\mathrm{A}$ is one of inhibitors of histone deacetylase and has a broad spectrum of epigenetic activities. Therefore, the present study focuses on evaluation of the efficacy of Trichostatin A against B.bovis and B.bigemina for cattle, B.caballi and T.equi for horses, B.gibsoni for dogs in vitro, and B. microti for mice and humans in vivo.

Trichostatin A (2 $\mathrm{mg} / \mathrm{kg})$ was performed in $\mathrm{BALB} / \mathrm{c}$ mice as previously described (4). 


\section{RESULTS}

The growth of B.bovis, B.bigemina, B.caballi, T.equi, and B.gibsoni was significantly inhibited $(P<0.05)$ by Trichostatin A at concentration of 5 nM. In the presence of $25 \mathrm{nM}$ of Trichostatin A, the growth of all parasites was completely suppressed on day 4. Subsequent viability tests showed that there was no re-growth of the five species of parasites at concentration of $5 \mathrm{nM}$ for Trichostatin A. Moreover, Trichostatin A affected the morphology of B.bovis, B.bigemina, B.caballi, T.equi, and B.gibsoni parasites in the treated cultures.
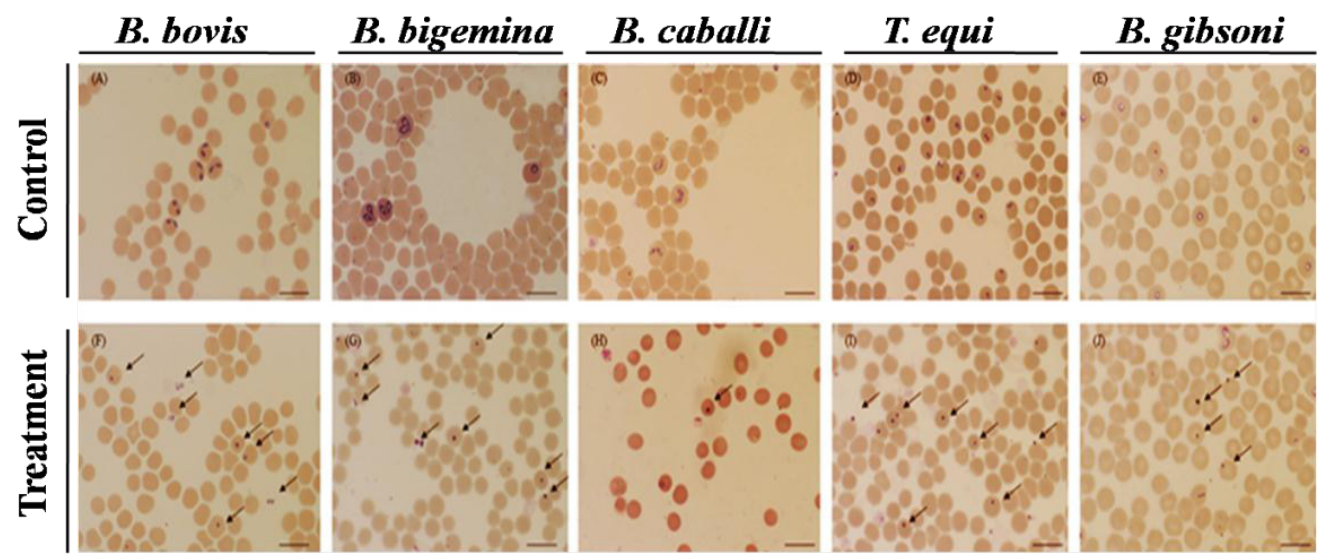

(Figure1. Morphological changes of trichostatin A-treated Babesia parasites. Severe morphological changes in $5 \mathrm{nM}$ trichostatin A-treated B.bovis $(\mathrm{F})$, B.bigemina $(\mathrm{G})$, B.caballi $(\mathrm{H})$, T.equi $(\mathrm{I})$, and B.gibsoni (J) after 3-day cultivation in comparison to the controls ((A) for B.bovis, (B) for B.bigemina, (C) for B.caballi, (D) for T.equi, and (E) B.gibsoni) are shown by arrows. Bar, $10 \mu \mathrm{m}$.).

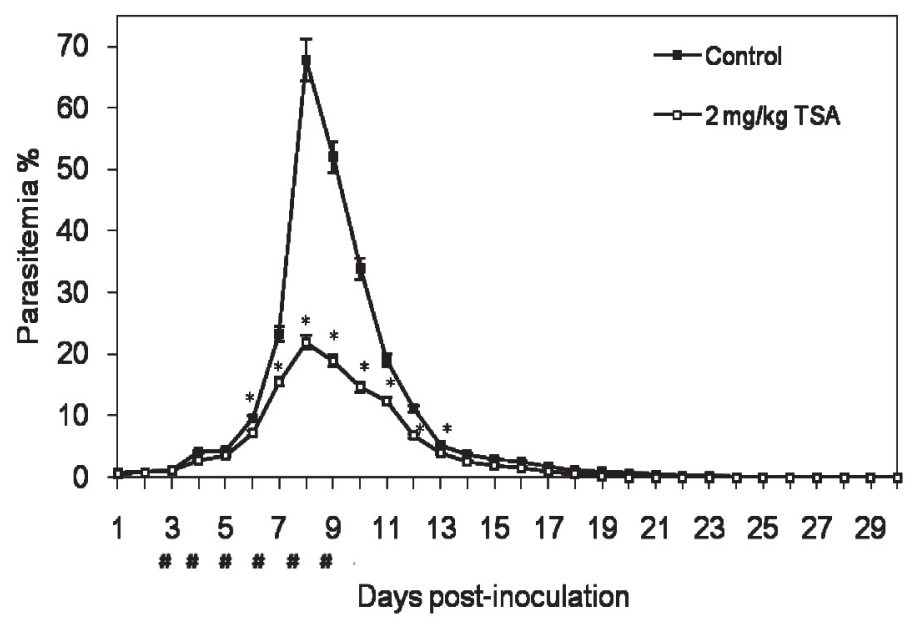

(Figure 2. Inhibitory effects of trichostatin A given intraperitoneally at the dose of $2 \mathrm{mg} / \mathrm{kg}$ on the in vivo growth of B.microti for observations of 5 mice per experimental group. Each value represents the mean \pm standard deviation for 2 experiments. Asterisks indicate a significant difference (Student's $t$ test $P<0.01$ ) from days 3 to 13 post-inoculation between the trichostatin A-treated and dimethyl sylfoxid, control group.) 


\section{DISCUSSION}

In this study, we conducted the first investigation of the in vitro and in vivo growth inhibition activity of histone deacetylase inhibitor, Trichostatin A, against bovine, equine, canine, and murine Babesia parasites. Exposure to higher concentrations of Trichostatin A completely suppressed the growth of bovine, equine, and canine Babesia parasites in in vitro cultures. Because treatment only with Dimethyl sylfoxid had no effect on parasitic growth, this growth inhibition of parasites was certainly due to effects of Trichostatin A.

Since Trichostatin A inhibited the growth of in vitro-cultured Babesia parasites, we evaluated its inhibitory effect in an in vivo model of $B$. microti in $\mathrm{BALB} / \mathrm{c}$ mice. No sign of toxicity was observed on

\section{REFERENCES}

1. T. Munkhjargal, M. Aboulaila, A. Ueno, T. Sivakumar, Y. Nakano, M. Yokoyama, N. Yokoyama, and I. Igarashi. Cloning and characterization of histone deacetylase from Babesia bovis. Veterinary Parasitology. 190(34), 423-433. Dec, 2012a.

2. T. Munkhjargal, M. Aboulaila, T. Sivakumar, N. Yokoyama, and I. Igarashi. Inhibitory effect of apicidin on in vitro and in vivo growth of Babesia parasites. The Journal of Protozoology Research. 19, 42-49. Jan, 2009.

3. T. Munkhjargal, T. Sivakumar, B. Badgar, T. Nyamjargal, B. Purevtseren, D. Bayarsaikhan, treated mice. B.microti was suppressed in mice treated with Trichostatin A for 6 days at the dose of $2 \mathrm{mg} / \mathrm{kg}$, with $78.1 \%$ inhibition on day 8 p.i. This result is in agreement with our previous study that apicidin inhibited the growth of murine Babesia parasite in vivo (2). Therefore, inhibitors of histone deacetylase such as Trichostatin A and apicidin at low doses are not toxic to mice and might be used for the safe treatment of babesiosis. In conclusion, our present findings showed that the efficacy of Trichostatin A on the growth of Babesia parasites in vitro and in vivo with the absence of any toxic side effects for the first time. Therefore, Trichostatin A might be an excellent target for the development of novel anti-babesial agents.

Aboulaila, M. A. Terkawi, B. Byambaa, N. Yokoyama, and I, Igarashi. Prevalence and genetic diversity of equine piroplasms in Tov province, Mongolia. Infection, Genetics and Evolutions. 14, 178-185. Feb, 2013.

4. T. Munkhjargal, M. Aboulaila, M. A. Terkawi, T. Sivakumar, I. Madoka, B. Davaasuren, T. Nyamjargal, N. Yokoyama, and I, Igarashi. Inhibitory effect of pepstatin A and mefloquine on the growth of Babesia parasites. American Journal of Tropical Medicine and Hygiene. 87(4), 681-688. Oct, 2012 b. 